Focal Therapy in Primary Localised Prostate Cancer $<$ ce:italic $>:</$ ce:italic $>$ The Europ... Page 1 of 8

Position Paper

\title{
Focal Therapy in Primary Localised Prostate Cancer: The European Association of Urology Position in 2018
}

Henk G. van der Poel ${ }^{a, *}$, Roderick C.N. van den Bergh ${ }^{a}$, Erik Briers ${ }^{b}$, Philip Cornford ${ }^{c}$, Alex Govorov ${ }^{d}$, Ann M. Henry ${ }^{e}$, Thomas B. Lam ${ }^{f, g}$, Malcolm D. Mason ${ }^{h}$, Olivier Rouvière ${ }^{i}$, Maria De Santis ${ }^{j, k}$, Peter-Paul M. Willemse ${ }^{l}$, Hendrik van Poppel ${ }^{m}$, Nicolas Mottet ${ }^{n}$

a Department of Urology, Netherlands Cancer Institute, Amsterdam, The Netherlands; ${ }^{\mathrm{b}}$ Patients Advocate, Hasselt, Belgium; ${ }^{\mathrm{c}}$ Royal Liverpool and Broadgreen Hospitals NHS Trust, Liverpool, UK; ${ }^{\mathrm{d}}$ Department of Urology, Moscow State University of Medicine and Dentistry, Moscow, Russia; ${ }^{\mathrm{e}}$ Leeds Cancer Centre, St. James's University Hospital, Leeds, UK; ' Academic Urology Unit, University of Aberdeen, Aberdeen, UK; ${ }^{\mathrm{g}}$ Department of Urology, Aberdeen Royal Infirmary,

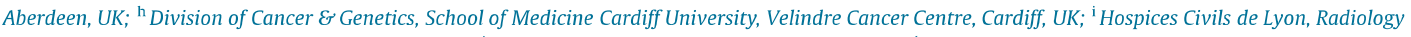
Department, Edouard Herriot Hospital, Lyon, France; ${ }^{\mathrm{j}}$ Clinical Trials Unit, University of Warwick, UK; ${ }^{\mathrm{k}}$ Department of Urology, Medical University of Vienna, Vienna, Austria; ${ }^{1}$ Department of Urology, University Utrecht, Utrecht, The Netherlands; ${ }^{\mathrm{m}}$ Department of Urology, University Hospital K.U. Leuven, Leuven, Belgium; ${ }^{\mathrm{n}}$ Department of Urology, University Hospital, St. Etienne, France

Article info

Article history:

Accepted January 2, 2018

Associate Editor:

James Catto

Keywords:

Prostate cancer

Focal therapy

Index lesion

Position paper

\begin{abstract}
Radical treatment of localised prostate cancer is recognised to be an unnecessary intervention or overtreatment in many men. Consequently, there has been a rapid uptake in the use of focal ablative therapies. However, there are several biological and practical concerns about such approaches as they have yet to be proved as robust treatment options. In particular, the multifocal nature of prostate cancer argues against unifocal treatment, while limitations in imaging can preclude the accurate identification of the number, location, and extent of prostate cancer foci. To date, a number of ablative options have reported results on mainly low-risk disease. Most series are relatively immature, with a lack of consistent follow-up, and the morbidity of retreatment is often not considered. The authors consider focal therapy to be an investigational modality, and encourage prospective recording of outcomes and recruitment of suitable patients.

Patient summary: Focal therapy of prostate cancer is the targeted destruction of cancer within a specific part of the prostate gland, sparing the rest of the prostate and nearby tissue. This procedure could potentially reduce side effects when compared with established standard treatments, such as surgery or radiotherapy, which treat the entire prostate. Studies show that for most men with low-risk cancer, active surveillance is the preferred treatment option. However, the available data regarding all forms of focal therapy are still poor and inconclusive. Consequently, due to both the lack of clear results associated with focal therapy and the difficulties in detecting all cancerous areas of the prostate, focal therapy should be considered an investigational modality only.
\end{abstract}

(C) 2018 European Association of Urology. Published by Elsevier B.V. All rights reserved.

* Corresponding author. Department of Urology, The Netherlands Cancer Institute Antoni Van Leeuwenhoek Hospital, Plesmanlaan 121, Amsterdam 1066CX, The Netherlands. Tel. +31205122553; Fax: +31205122554

E-mail addresses: h.vd.poel@nki.nl, h_vanderpoel@hotmail.com (H.G. van der Poel).

https://doi.org/10.1016/j.eururo.2018.01.001

0302-2838/@ 2018 European Association of Urology. Published by Elsevier B.V. All rights reserved. 
Focal Therapy in Primary Localised Prostate Cancer $<$ ce:italic $>:</$ ce:italic $>$ The Europ... Page 2 of 8

\section{Introduction}

Whole-gland treatment is currently considered the optimum treatment for localised prostate cancer (PCa). However, since treatment of the entire prostate gland results in damage to surrounding tissue such as urinary sphincter, neurovascular bundle, bowel, and bladder, focused treatment for $\mathrm{PCa}$ lesions only, should they be accurately identified, would be of interest. Focal therapy (FT) of the prostate can be defined as treatment of specific areas of the prostate to minimise treatment-related morbidity and is facilitated by improvements in PCa imaging. The options for FT are numerous, and focal ablation may reduce complications associated with whole-gland treatment provided that the same oncological efficacy is maintained [1,2].

Recent data from the ProtecT trial showed no difference in 10-yr cancer-specific survival between active monitoring, radical prostatectomy (RP), and external beam radiotherapy (EBRT) in men with mainly low- and intermediate-risk PCa, but considerable differences in functional outcomes

Table 1 - Summary of consensus reports on focal therapy

\begin{tabular}{|c|c|c|c|c|c|}
\hline Publication & Consensus topic & Consensus set-up & Patient selection & Follow-up & Conclusion \\
\hline $\begin{array}{l}\text { Bostwick et al } \\
\text { (2007) [7] }\end{array}$ & $\begin{array}{l}\text { Pathobiology } \\
\text { definition, patient } \\
\text { selection, biopsy }\end{array}$ & Not provided & $\begin{array}{l}\text { LE }>5 \mathrm{yr} \text {, T1-3, PSA }<15 \mathrm{ng} / \mathrm{ml} \text {, no } \\
\text { LUTS, bladder stones, infections } \\
\text { excluded, 3D mapping biopsies at } \\
5 \mathrm{~mm} \text { interval }\end{array}$ & & $\begin{array}{l}\text { FT reasonable consideration } \\
\text { in selected patients }\end{array}$ \\
\hline $\begin{array}{l}\text { De la Rosette } \\
\text { et al }(2010) \\
{[8]}\end{array}$ & $\begin{array}{l}\text { Patient selection, } \\
\text { imaging }\end{array}$ & $\begin{array}{l}\text { Workshop, } \\
\text { discussion group, } \\
\text { informal }\end{array}$ & $\begin{array}{l}\text { Template biopsies, LE }>10 \mathrm{yr} \text {, cave in } \\
\text { patients with LUTS, low-intermediate } \\
\text { risk, }<\mathrm{T} 2 \mathrm{c} \text {, anterior/apical lesions may } \\
\text { be difficult, long-term effects not } \\
\text { known }\end{array}$ & $\begin{array}{l}\text { Biopsy } 6 \text { and } 12 \mathrm{mo} \text {; } \\
\text { future: mpMRI or } \\
\text { CEUS, } 3 \text { mo PSA in the } \\
\text { 1st year and } 6 \text { mo } \\
\text { thereafter, PROMs }\end{array}$ & \\
\hline $\begin{array}{l}\text { Smeenge et al } \\
\text { (2012) [9] }\end{array}$ & Role of TRUS & $\begin{array}{l}\text { Workshop, } \\
\text { discussion group, } \\
\text { informal }\end{array}$ & $\begin{array}{l}\text { TRUS value limited, CEUS promising, } \\
\text { systematic biopsy schemes needed }\end{array}$ & & \\
\hline $\begin{array}{l}\text { Ahmed et al } \\
(2012)[10]\end{array}$ & FT and AS & $\begin{array}{l}\text { Workshop, } \\
\text { discussion group, } \\
\text { informal }\end{array}$ & Transperineal mapping biopsy & & $\begin{array}{l}\text { Suggested study sequence: } \\
\text { proof of tumour ablation, } \\
\text { compare FT with existing } \\
\text { whole gland and/or AS }\end{array}$ \\
\hline $\begin{array}{l}\text { Langley et al } \\
\text { (2012) [11] }\end{array}$ & Focal LDR & Consensus meeting & $\begin{array}{l}\mathrm{LE}>10 \mathrm{yr}, \mathrm{PSA} \leq 15 \mathrm{ng} / \mathrm{ml}, \mathrm{mpMRI}, \\
\text { template biopsies, unilateral }<0.5 \mathrm{cc} \text {, } \\
\text { contralateral }<3 \mathrm{~mm} \text { insignificant } \\
\text { disease }(\mathrm{GS} 3+3,<3 \mathrm{~mm}) \text {, index lesion } \\
\leq \mathrm{GS} 3+4,<\mathrm{T} 2 \mathrm{c} \text {, prostate size }<60 \mathrm{cc}\end{array}$ & $\begin{array}{l}\text { PSA } 3 \text { mo intervals for } \\
1 \text { yr and } 6 \text { mo } \\
\text { thereafter, Phoenix } \\
\text { criteria, mpMRI, } \\
\text { PROMs }\end{array}$ & $\begin{array}{l}\text { Distinction of ultra-FT (part } \\
\text { of lobe), FT (hemigland), } \\
\text { focused therapy (combining } \\
\text { whole gland and FT) }\end{array}$ \\
\hline $\begin{array}{l}\text { Muller et al } \\
(2014)[12]\end{array}$ & Role of mpMRI & $\begin{array}{l}\text { Delphi method, } \\
\text { panel meeting }\end{array}$ & & Biopsy $6 \mathrm{mo}, 12 \mathrm{mo}$ & $\begin{array}{l}\text { mpMRI preferred imaging, } \\
\text { FU } 6 \text { mo, yearly mpMRI, no } \\
\text { consensus on whether } \\
\text { mpMRI could replace } \\
\text { biopsies }\end{array}$ \\
\hline $\begin{array}{l}\text { Van den Bos } \\
\text { et al (2014) } \\
{[13]}\end{array}$ & Trial design & $\begin{array}{l}\text { Delphi method, } \\
\text { panel meeting }\end{array}$ & $\begin{array}{l}\mathrm{PSA}<15 \mathrm{ng} / \mathrm{ml}, \mathrm{T} 1 \mathrm{c}-2 \mathrm{a}, \mathrm{GS} 3+3 \text { or } 3 \\
+4, \mathrm{LE}>10 \mathrm{yr}\end{array}$ & Biopsy $6 \mathrm{mo}, 12 \mathrm{mo}$ & \\
\hline $\begin{array}{l}\text { Muller et al } \\
(2015)[14]\end{array}$ & Follow-up & $\begin{array}{l}\text { Delphi method, } \\
\text { panel meeting }\end{array}$ & & $\begin{array}{l}\text { Minimal } 5 \mathrm{yr} \text { (fusion) } \\
\text { template TRUS biopsies } \\
\text { after } 1 \mathrm{yr} \text {, mpMRI } \\
\text { (T2WI, DWI, DCE, } \\
\text { T1WI) at } 6 \text { and } 12 \mathrm{mo} \text {, } \\
\text { yearly thereafter until } \\
5 \text { yr }\end{array}$ & \\
\hline $\begin{array}{l}\text { Donaldson } \\
\text { et al (2015) } \\
\text { [15] }\end{array}$ & $\begin{array}{l}\text { Patients, } \\
\text { interventions and } \\
\text { outcomes }\end{array}$ & $\begin{array}{l}\text { Delphi method, } \\
\text { panel meeting }\end{array}$ & $\begin{array}{l}\text { Intermediate risk, MRI-targeted or } \\
\text { template biopsies, } 5 \mathrm{~mm} \text { treatment } \\
\text { margin, GS } 6,<3 \mathrm{~mm} \text { can be left } \\
\text { untreated, }<20 \% \text { retreatment }\end{array}$ & & \\
\hline $\begin{array}{l}\text { Scheltema } \\
\text { et al (2017) } \\
\text { [16] }\end{array}$ & mpMRI & $\begin{array}{l}\text { Delphi method, } \\
\text { panel meeting }\end{array}$ & mpMRI to plan treatment & Biopsy & $\begin{array}{l}\text { Use } 1.5 \mathrm{~T} \text { mpMRI only with } \\
\text { endorectal coil, fusion MRI- } \\
\text { TRUS when suspect lesion } \\
\text { besides systemic biopsies }\end{array}$ \\
\hline $\begin{array}{l}\text { Tay et al } \\
\text { (2017) [17] }\end{array}$ & Patient selection & $\begin{array}{l}\text { Delphi method, } \\
\text { panel meeting }\end{array}$ & $\begin{array}{l}\text { mpMRI standard imaging tool, low/ } \\
\text { intermediate-risk PCa, GS } 4+3, \text { GS } 3 \\
+4 \text {, foci }<1.5 \text { cc on mpMRI, }<20 \% \text { of the } \\
\text { prostate, } 3 \text { cc or } 25 \% \text { of the prostate for } \\
\text { hemigland treatment; Gleason } 6 \text { in one } \\
\text { core in the nontreated region is } \\
\text { acceptable }\end{array}$ & & \\
\hline
\end{tabular}


[3]. Since FT has mainly been performed in smaller low-risk lesions where active surveillance (AS) is a valid option, the efficacy of FT should be compared with that of AS and, as such, long-term follow-up studies are required. In intermediate-risk lesions, a comparable oncological outcome with a lower side-effect profile would be the main advantages of FT in comparison with whole-gland treatment, in a situation where an active treatment is needed.

To date, most FTs have been achieved with ablative technologies: cryotherapy, high-intensity focused ultrasound (HIFU), photodynamic therapy, electroporation, and focal radiotherapy by brachytherapy or stereotactic EBRT. All reported modalities of FT are at Idea, Development, Exploration, Assessment and Long-term follow-up Framework (IDEAL) stage $2 \mathrm{~b}$, that is, they are at an exploratory phase, with assessment and longer follow-up not yet available [4] with the exception of photodynamic therapy where randomised clinical trial (RCT) data are available (IDEAL phase 3) [5].

The literature search used for this position paper was similar to that used for the EAU PCa guidelines [6].

The concept of FT can only provide long-term benefit to patients if it satisfies the following requirements:

1. Survival efficacy at least equivalent to standard of care (SOC)

2. Fewer complications and functional side effects compared with SOC

3. Reliable follow-up of remaining prostatic tissue

4. Potential secondary or salvage treatment not impaired by the primary FT

Although FT has also been used for salvage treatments of PCa following local recurrences after whole-gland treatment, this paper will focus on primary treatment only.

\section{Patient selection}

Detailed local staging is essential for selecting patients suitable for focal gland treatment. Several consensus meetings have strived to define criteria for patient selection (Table 1) [7-17]. In the most recent publications, these criteria have been men with low-risk (GS $3+3$ ) tumours and life expectancy of at least $10 \mathrm{yr}$. Nowadays, AS is considered to be a valid option in these patients, as well as whole-gland treatments. Any form of FT in low-risk PCa should be associated with significant clinical benefit compared with these SOC. Patients with a small Gleason 7 (Gleason sum score $3+4$, ISUP 2) lesion might be better candidates, although, so far, this group has rarely been considered in the published trials. Multiparametric magnetic resonance imaging (mpMRI) has been used to select patients in clinical trials [18-21] and is the standard imaging tool for FT, allowing targeted biopsies. However, an international consensus project recognised that addition of systematic biopsies remains essential to accurately stage diseases [16]. These imaging and sampling modalities must be associated with a high negative predictive value of significant PCa in regions considered as "normal". Sextant random biopsies are insufficient to accurately map tumour locations within the prostate. Instead, standardised, preferably perineal template-guided saturation, biopsies are suggested to aid patient selection [19,22-24].

\section{Techniques of FT}

Several ablative and radiotherapy approaches to FT have been reported. Comparative studies are scarce, and most studies included low- to intermediate-risk PCa treated with curative intent. Regardless of the technique, total ablation of the tumour within the treated area is crucial. Several treatment templates have been chosen, including hemigland, quadrant, and lesion targeting. Attempts have been made to identify the index lesion, that is, the largest lesion with the highest Gleason grade in the prostate, to target for FT. In $20 \%$ of cases, however, high-grade tumour cells can be found in nontargeted smaller lesions [25], questioning the validity of this approach. When selecting foci for treatment [15], planning should include a 5$\mathrm{mm}$ margin to account for microscopic spread and targeting error, although other authors have suggested a larger safety margin to be important [26]. Foci of indolent cancer, which can also be present in the prostate, might be left untreated when treating the dominant index lesion. Table 2 shows the techniques used for FT of primary PCa.

Table 2 - Focal therapy options for primary prostate cancer management

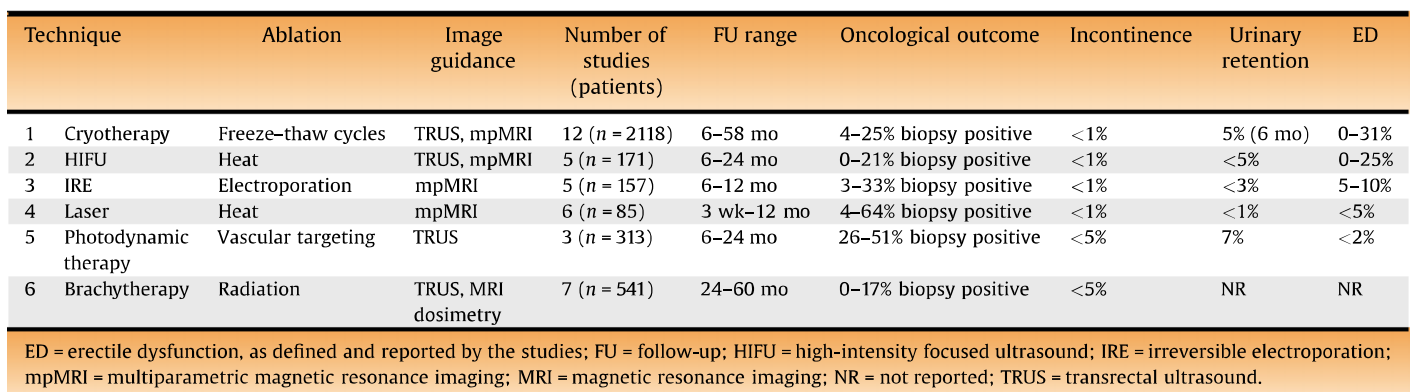




\subsection{Focal cryosurgery ablation of the prostate}

Cryotherapy uses freezing of tissue under ultrasound (US) guidance in one or multiple cycles to ablate tissue. This results in a combination of protein denaturation, direct rupture of cellular membranes by ice crystal formation, vascular stasis with the development of microthrombi, and consecutive ischaemic apoptosis. Biochemical recurrence (BCR) at 60 mo for focal cryosurgery ablation of the prostate (fCSAP) was comparable with whole-gland treatment, with better erectile function preservation for fCSAP but similar incidence of voiding problems and fistulas [27]. The short follow-up and comparison of different definitions of BCR render conclusions on oncological efficacy problematic. The incontinence rates at $1 \mathrm{yr}$ for fCSAP were very low $(<1 \%)$ while erectile dysfunction rates (ranging from $0 \%$ to $40 \%$ ) were close to those for men after RP. Procedural complication rates were generally low, with the most common being acute urinary retention (range 1.2-8.0\%) and a low incidence of fistula formation $(<0.5 \%)$. When compared with whole-gland cryotherapy, fCSAP resulted in a higher rate of erectile function preservation, while continence and oncological outcomes were similar for both options [28]. Using mpMRI guidance, fCSAP resulted in no deterioration in erectile function from baseline, and lower urinary tract symptoms remained unchanged from baseline [29].

\subsection{Focal HIFU}

The principle of HIFU ablation is to focus a high-intensity US beam on a given target point. Concentration of the beam energy at that point produces a dramatic temperature rise (up to $80^{\circ} \mathrm{C}$ in a few seconds). Tissue destruction is caused by coagulation necrosis and cavitation effects. Systematic reviews (SRs) of the literature, comparing outcomes of foca (fHIFU) with those of RP or EBRT, found no comparative studies reporting on oncological continence or potency at $1 \mathrm{yr}$ or more [30]. In a low-to-intermediate risk population treated by hemiablation, the local radical retreatment rate was $11 \%$ at 2 yr with a $13 \%$ grade- 3 adverse event rate [31]. In five patients who underwent MR-guided focal ablation before RP, no residual cancer was found in the treated area, but Gleason 7 bilateral cancer, overlooked by mpMRI, was present outside the treated area in two of five patients [32]. Three out of 14 men in a small series with mpMRIguided fHIFU were diagnosed with Gleason 7 or higher cancer at 24 mo after treatment [33]. Barret et al [34] reported a reduction in the International Index of Erectile Function score after fHIFU and a moderate increase in the International Prostate Symptom Score, suggesting that fHIFU carries some morbidity.

\subsection{Irreversible electroporation and radiofrequency ablation}

Irreversible electroporation (IRE) applies electric current to ablate tissue with a small transition zone between treated and nontreated tissue [35]. However, the IRE ablation zone cannot be sufficiently visualised by transrectal ultrasonography guidance, and although contrast-enhanced US and mpMR show promising results, difficulties in targeting tissue remain unresolved [36-38]. This is confirmed by recent data, which showed a narrow safety margin as a strong predictor of local treatment failure [39] with an in-field recurrence rate of $16 \%$. In 19 men treated with nanoknife IRE, residual disease was found in $39 \%$ [40]. Toxicity after IRE is low for erectile dysfunction $(<10 \%)$ and urinary retention (3\%; Table 2 ).

\subsection{Focal laser ablation}

MRI-guided laser treatment allows for thermal ablation of specific areas of the prostate [41-44]. A phase I study, where laser ablation was followed by prostatectomy in five men, revealed higher correlation between T1-weighed MRI ablation volume and final histology [44]. In five reported series, follow-up was less than $1 \mathrm{yr}$ and residual disease was present in up to $22 \%$ of cases [41]. In-bore MRI guidance may improve outcome [45]. Toxicity for focal laser ablation is reported in $<5 \%$ of patients, and high-grade toxicity did not occur in a series of 11 patients [45].

\subsection{Photodynamic focal therapy}

Photosensitisers can be used to ablate tissue by applying light. Formation of oxygen radicals is believed to underlie the thromboembolic effects of photodynamic therapy. Photodynamic FT (PFT) is the only FT for PCa that was evaluated in a randomised phase III clinical trial comparing hemigland ablation $(n=207)$ and AS $(n=206)$ in men with low-risk disease. This level $1 \mathrm{~b}$ evidence showed a reduced rate of positive prostate biopsies at $2 \mathrm{yr}$ in the PFT arm as the primary end point $[5,46]$. In September 2017, the European Medicines Agency granted marketing authorisation of PFT by padeliporfin for low-risk unilateral PCa. Although valid at the time of initiation, the study was criticised for including men with low-risk disease who, according to current standard practice, would all be offered AS; therefore, the clinical relevance of this finding is, at the very least, questionable. Longer follow-up studies are needed to evaluate overall survival (OS) data. The most common toxicity for PFT was urinary retention in $7 \%$ of cases early after treatment.

\subsection{Focal brachytherapy}

In an SR, Peach et al [47] described data from six clinical studies and nine dosimetry studies on focal high- and lowdose-rate brachytherapy. Follow-up in all studies was $<60$ mo, and the recurrence rate was found to be up to $29 \%$ in one series. Toxicity was less than, or similar to, that for wholegland brachytherapy, but this was found to be dependent on the location of the treated lesion [48]. Targeting the peripheral zone only by iodine- 125 sources was found to be associated with high recurrence rates in intermediate-risk patients [49]. In comparison with whole-gland brachytherapy, focal brachytherapy resulted in a markedly lower prostate-specific antigen (PSA) reduction in a small group of men [50]. Toxicity was reported as less than, or similar to, whole-gland treatment, but detailed data are lacking. 


\section{Statements \\ 4.1. Can FT treat the tumour cell clones most likely to} metastasise?

The concept of FT is valid when the potentially metastasising tumour clones can be identified and therefore targeted. The frequent multifocality of PCa argues for accurate imaging and histology, which is generally obtained by mpMRI and mapping template biopsies. Potentially metastasising clones may appear early in the course of the disease [51,52]. Although mpMRI is promising for identifying larger lesions, it lacks sufficient sensitivity for the detection of smaller lesions, and additional template biopsies are recommended for more accurate staging and better patient selection [53]. In-field recurrences occur after most focal ablative treatments, and the toxicity of secondary treatments for recurrent disease is less well known; therefore, further data are essential.

FT can ablate cancer cells, but currently, imaging methods cannot reliably identify all high-risk cancer clones within the prostate.

4.2. What is the evidence regarding the clinical effectiveness of FT for localised PCa?

Two recent SRs summarised the data regarding clinical effectiveness of FT. Ramsay et al [54] undertook an SR and network meta-analysis of ablative therapy in men with localised PCa, which included a subgroup analysis of FT versus RP and EBRT. Nine case series reporting on FT were identified (five studies reporting on fCSAP, three studies reporting on fHIFU, and one study reporting on both). For FT versus RP or EBRT, no statistically significant differences were found for BCR at $3 \mathrm{yr}$. For fHIFU versus RP or EBRT, again, there were no data to compare oncological outcomes at $\geq 1 \mathrm{yr}$, making it impossible to assess oncological effectiveness of FT. The high risk of bias and the overall poor data quality of published papers preclude any reliable conclusions [54].

Similarly, Valerio et al [30], in an SR including data from 3230 patients across 37 studies, covering seven different energy sources for FT, found that the toxicity of FT is low, but due to lack of a comparator group in most studies, evaluation against $S O C$ remains to be done.

It should be recognised that most studies on FT include men with low-risk disease for whom AS is the preferred option. Short-term results from the only RCT comparing FT and AS are promising. The coprimary end points were treatment failure at $2 \mathrm{yr}$ (histological progression based on an increased number of positive cores, an increase in the length of cancer, an increased Gleason score, an increased PSA of $>10 \mathrm{ng} / \mathrm{ml}$, or an increased T stage) and absence of definite cancer. Significantly reduced treatment failure was observed with FT even if evidence of clinical benefit is still missing and clearly deserves longer follow-up [5]. Remarkable variations in follow-up intervals and positive biopsy rates is apparent among studies (Table 1), possibly reflecting the experimental setup of most studies.
The literature suggests that the oncological effectiveness of FT remains unproven due to the lack of reliable comparative data against SOC including AS. We recommend awaiting prospective comparative trial data before implementing FT in routine clinical practice.

4.3. How does FT compare with whole-gland treatment in terms of complications?

Toxicity of whole-gland treatment of localised PCa is caused by damage to surrounding anatomical structures and depends on the treatment modality [55]. Although less frequent, reports on non-whole-gland ablative treatment show similar types of toxicity to whole-gland treatment [1,34], but with earlier recovery [56]. Phase III data suggest that toxicity of photodynamic hemiablation exceeds side effects of AS in the initial $2 \mathrm{yr}$ after treatment [46].

FT studies targeting smaller regions of the prostate have reported reduced toxicity compared with wholegland treatment options, but robust comparative studies with toxicity end points are still lacking.

4.4. Is reliable follow-up of remaining prostatic tissue after FT for cancer progression possible?

Close follow-up is essential after FT, since residual disease in the prostate may lead to disease recurrence and/or progression. Neither PSA nor imaging has been standardised to define recurrence/progression after FT [30]. A consensus panel [15] recommended that histological outcomes are assessed by targeted biopsy at $1 \mathrm{yr}$ after treatment [16]. Residual disease in the treated area of $<3 \mathrm{~mm}$ in size and of Gleason $3+3$ score was not considered to be in need of further treatment, and focal retreatment rates of $<20 \%$ were considered clinically acceptable. The need for subsequent whole-gland treatment should be categorised as failure. Muller et al [14] presented results from a consensus meeting on follow-up after FT. Consensus was achieved for at least $5 \mathrm{yr}$ of followup using mpMRI, biopsies, and functional outcome assessment. A major limitation of FT studies is the lack of a uniform definition of disease recurrence. For comparison with other local therapies, comparative studies are needed.

Given the considerable uncertainties regarding the optimal follow-up of men treated with FT, patients should only be treated within the context of a clinical trial using predefined criteria [6].

4.5. Is there increased toxicity for salvage treatment following failed FT/recurrence after FT compared with the initial whole-gland treatment?

Local recurrence after FT has been reported in 3.6-40\% of cases $[1,20,34]$. Several studies reported data on the toxicity of secondary treatment after FT [57-59]. Local salvage therapy after primary whole-gland treatment is usually associated with increased morbidity compared with pri- 
Focal Therapy in Primary Localised Prostate Cancer $<$ ce:italic $>:</$ ce:italic $>$ The Europ... Page 6 of 8

mary whole-gland treatment [60-63]. Complications seem similar for salvage RP after whole-gland treatment and FT, but appear to be related to the type of primary FT $[57,64]$. Data on retreatment with FT in men with recurrence are scarce.

Better understanding of the toxicity of secondary treatments and retreatments after FT is needed, and its assessment should be part of prospective investigations.

\section{Conclusions}

FT may reduce the toxicity of whole-gland management while retaining cancer control. However, before widespread clinical introduction, clear, predefined, clinically relevant objectives are needed, such as a negative biopsy, OS, disease-specific survival and toxicity, as well as optimal follow-up schedules. Based on the available data, it should be recognised that AS is the preferred option for many men with low-risk PCa. It is unlikely that FT will provide any oncological benefits in this population within $10 \mathrm{yr}$ of diagnosis, considering the low cancer-specific mortality. In intermediate-risk disease, accurate detection of higher-risk clones remains problematic and the paucity of relevant data regarding clinical outcome in such situations is highly problematic. Patients should be counselled and cautioned that no long-term comparative data on functional and oncological outcomes are available for FT. The presence of grade I-III toxicity occurs in up to $28 \%$ of cases [31] and the need for retreatment exists, along with its associated toxicities. Finally, no clear follow-up strategy has been clarified irrespective of the risk group considered. If long-term benefit is proved (functional or oncological), FT would represent significant progress in PCa care. However, thus far, FT must be considered an investigational modality only.

Author contributions: Henk G. van der Poel had full access to all the data in the study and takes responsibility for the integrity of the data and the accuracy of the data analysis.

Study concept and design: van der Poel, Mottet, van Poppel. Acquisition of data: van der Poel.

Analysis and interpretation of data: van der Poel, Mottet.

Drafting of the manuscript: van der Poel.

Critical revision of the manuscript for important intellectual content: van der Poel, van den Bergh, Briers, Cornford, De Santis, Govorov, Henry, Lam, Mason, Rouvière, Willemse, Poppel, Mottet.

Statistical analysis: None.

Obtaining funding: None.

Administrative, technical, or material support: van der Poel.

Supervision: Mottet, van Poppel.

Other: None.

Financial disclosures: Henk G. van der Poel certifies that all conflicts of interest, including specific financial interests and relationships and affiliations relevant to the subject matter or materials discussed in the manuscript (eg, employment/affiliation, grants or funding consultancies, honoraria, stock ownership or options, expert testimony, royalties, or patents filed, received, or pending), are the following: None.

Funding/Support and role of the sponsor: None.

\section{References}

[1] Valerio M, Ahmed HU, Emberton M, et al. The role of focal therapy in the management of localised prostate cancer: a systematic review. Eur Urol 2014;66:732-51.

[2] Baydoun A, Traughber B, Morris N, et al. Outcomes and toxicities in patients treated with definitive focal therapy for primary prostate cancer: systematic review. Future Oncol 2017;13:649-63.

[3] Hamdy FC, Donovan JL, Lane JA, et al. 10-Year outcomes after monitoring, surgery, or radiotherapy for localized prostate cancer. N Engl J Med 2016;375:1415-24.

[4] McCulloch P, Altman DG, Campbell WB, et al. No surgical innovation without evaluation: the IDEAL recommendations. Lancet 2009; 374:1105-12.

[5] Azzouzi A-R, Vincendeau S, Barret S, et al. Padeliporfin vasculartargeted photodynamic therapy versus active surveillance: a randomised clinical trial in men with low-risk prostate cancer. Lancet Oncol 2017; 18:181-91.

[6] Mottet N, Bellmunt J, Bolla M, et al. EAU-ESTRO-SIOG guidelines on prostate cancer. Part 1: screening, diagnosis, and local treatment with curative intent. Eur Urol 2017;71:618-29.

[7] Bostwick DG, Waters DJ, Farley ER, et al. Group consensus reports from the Consensus Conference on Focal Treatment of Prostatic Carcinoma, Celebration, Florida, February 24, 2006. Urology 2007;70(6 Suppl):42-4

[8] de la Rosette J, Ahmed H, Barentsz J, et al. Focal therapy in prostate cancer-report from a consensus panel. J Endourol 2010:24:775-80.

[9] Smeenge M, Barentsz J, Cosgrove D, et al. Role of transrectal ultrasonography (TRUS) in focal therapy of prostate cancer: report from a consensus panel. BJU Int 2012;110:942-8.

[10] Ahmed HU, Akin O, Coleman JA, Crane S, Emberton M, Goldenberg L et al. Transatlantic Consensus Group on active surveillance and focal therapy for prostate cancer. BJU Int 2012;109:1636-47.

[11] Langley S, Ahmed HU, Al-Qaisieh B, et al. Report of a consensus meeting on focal low dose rate brachytherapy for prostate cancer. BJU Int 2012;109(Suppl 1):7-16.

[12] Muller BG, van den Bos W, Brausi M, et al. Role of multiparametric magnetic resonance imaging (MRI) in focal therapy for prostate cancer: a Delphi consensus project. BJU Int 2014;114:698-707.

[13] van den Bos W, Muller BG, Ahmed H, et al. Focal therapy in prostate cancer: international multidisciplinary consensus on trial design. Eur Urol 2014;65:1078-83.

[14] Muller BG, van den Bos W, Brausi M, et al. Follow-up modalities in focal therapy for prostate cancer: results from a Delphi consensus project. World J Urol 2015;33:1503-9.

[15] Donaldson IA, Alonzi R, Barratt D, et al. Focal therapy: patients, interventions, and outcomes-a report from a consensus meeting. Eur Urol 2015;67:771-7.

[16] Scheltema MJ, Tay KJ, Postema AW, et al. Utilization of multiparametric prostate magnetic resonance imaging in clinical practice and focal therapy: report from a Delphi consensus project. World J Urol 2017;35:695-701.

[17] Tay KJ, Scheltema MJ, Ahmed HU, et al. Patient selection for prostate focal therapy in the era of active surveillance: an international Delphi consensus project. Prostate Cancer Prostatic Dis 2017;20:294-9.

[18] Siddiqui MM, Rais-Bahrami S, Truong H, et al. Magnetic resonance imaging/ultrasound-fusion biopsy significantly upgrades prostate cancer versus systematic 12-core transrectal ultrasound biopsy. Eur Urol 2013;64:713-9.

[19] Singh PB, Anele C, Dalton E, et al. Prostate cancer tumour features on template prostate-mapping biopsies: implications for focal therapy. Eur Urol 2014;66:12-9.

[20] Ahmed HU, Dickinson L, Charman S, et al. Focal ablation targeted to the index lesion in multifocal localised prostate cancer: a prospective development study. Eur Urol 2015;68:927-36. 
Focal Therapy in Primary Localised Prostate Cancer $<$ ce:italic $>:</$ ce:italic $>$ The Europ... Page 7 of 8

[21] Tran M, Thompson J, Bohm M, et al. Combination of multiparametric MRI and transperineal template-guided mapping biopsy of the prostate to identify candidates for hemi-ablative focal therapy. BJU Int 2016;117:48-54.

[22] Onik G, Miessau M, Bostwick DG. Three-dimensional prostate mapping biopsy has a potentially significant impact on prostate cancer management. J Clin Oncol 2009;27:4321-6.

[23] Crawford ED, Rove KO, Barqawi AB, et al. Clinical-pathologic correlation between transperineal mapping biopsies of the prostate and three-dimensional reconstruction of prostatectomy specimens. Prostate 2013;73:778-87

[24] Crawford ED, Wilson SS, Torkko KC, et al. Clinical staging of prostate cancer: a computer-simulated study of transperineal prostate biopsy. BJU Int 2005;96:999-1004.

[25] Wise AM, Stamey TA, McNeal JE, Clayton JL. Morphologic and clinical significance of multifocal prostate cancers in radical prostatectomy specimens. Urology 2002;60:264-9.

[26] Le Nobin J, Orczyk C, Deng FM, et al. Prostate tumour volumes: evaluation of the agreement between magnetic resonance imaging and histology using novel co-registration software. BJU Int 2014;114:E105-12.

[27] Mendez MH, Passoni NM, Pow-Sang J, Jones JS, Polascik TJ. Comparison of outcomes between preoperatively potent men treated with focal versus whole gland cryotherapy in a matched population. J Endourol 2015;29:1193-8.

[28] Tay KJ, Polascik TJ, Elshafei A, Tsivian E, Jones JS. Propensity scorematched comparison of partial to whole-gland cryotherapy for intermediate-risk prostate cancer: an analysis of the Cryo On-Line Data Registry Data. J Endourol 2017;31:564-71.

[29] Valerio M, Shah TT, Shah P, et al. Magnetic resonance imagingtransrectal ultrasound fusion focal cryotherapy of the prostate: a prospective development study. Urol Oncol 2017;35, 150 e1-7.

[30] Valerio M, Cerantola Y, Eggener SE, et al. New and established technology in focal ablation of the prostate: a systematic review. Eur Urol 2016;71:17-34

[31] Rischmann P, Gelet A, Riche B, et al. Focal high intensity focused ultrasound of unilateral localized prostate cancer: a prospective multicentric hemiablation study of 111 patients. Eur Urol 2017;71:267-73.

[32] Napoli A, Anzidei M, De Nunzio C, et al. Real-time magnetic resonance-guided high-intensity focused ultrasound focal therapy for localised prostate cancer: preliminary experience. Eur Urol 2013;63:395-8.

[33] Tay KJ, Cheng CWS, Lau WKO, Khoo J, Thng CH, Kwek JW. Focal therapy for prostate cancer with in-bore MR-guided focused ultrasound: two-year follow-up of a phase I trial-complications and functional outcomes. Radiology 2017;285:620-8.

[34] Barret E, Ahallal Y, Sanchez-Salas R, et al. Morbidity of focal therapy in the treatment of localized prostate cancer. Eur Urol 2013;63:61822.

[35] Davalos RV, Bhonsle S, Neal 2nd RE. Implications and considerations of thermal effects when applying irreversible electroporation tissue ablation therapy. Prostate 2015;75:1114-8.

[36] Beyer LP, Pregler B, Niessen C, et al. Percutaneous irreversible electroporation (IRE) of prostate cancer: contrast-enhanced ultrasound (CEUS) findings during follow up. Clin Hemorheol Microcirc 2016;64:501-6.

[37] van den Bos W, de Bruin DM, van Randen A, et al. MRI and contrastenhanced ultrasound imaging for evaluation of focal irreversible electroporation treatment: results from a phase I-II study in patients undergoing IRE followed by radical prostatectomy. Eur Radiol 2016;26:2252-60.

[38] Wendler JJ, Ganzer R, Hadaschik B, et al. Why we should not routinely apply irreversible electroporation as an alternative cura- tive treatment modality for localized prostate cancer at this stage. World J Urol 2017;35:11-20.

[39] van den Bos W, Scheltema MJ, Siriwardana AR, et al. Focal irreversible electroporation as primary treatment for localized prostate cancer. BJU Int 2018;121:716-24.

[40] Valerio M, Dickinson L, Ali A, et al. Nanoknife Electroporation Ablation Trial: a prospective development study investigating focal irreversible electroporation for localized prostate cancer. J Urol 2017;197(3 Pt 1):647-54.

[41] Oto A, Sethi I, Karczmar G, et al. MR imaging-guided focal laser ablation for prostate cancer: phase I trial. Radiology 2013;267:932-40.

[42] Lepor H, Llukani E, Sperling D, Futterer JJ. Complications, recovery, and early functional outcomes and oncologic control following inbore focal laser ablation of prostate cancer. Eur Urol 2015;68:924-6.

[43] Natarajan S, Raman S, Priester AM, et al. Focal laser ablation of prostate cancer: phase I clinical trial. J Urol 2016;196:68-75.

[44] Bomers JG, Cornel EB, Futterer JJ, etal. MRI-guided focallaser ablation for prostate cancer followed by radical prostatectomy: correlation of treatment effects with imaging. World J Urol 2017;35:703-11.

[45] Natarajan S, Jones TA, Priester AM, et al. Focal laser ablation of prostate cancer: feasibility of MRI/US fusion for guidance. J Urol 2017; 198:839-47.

[46] Azzouzi AR, Barret E, Moore CM, et al. $\operatorname{TOOKAD((R))~soluble~vascu-~}$ lar-targeted photodynamic (VTP) therapy: determination of optimal treatment conditions and assessment of effects in patients with localised prostate cancer. BJU Int 2013;112:766-74.

[47] Peach MS, Trifiletti DM, Libby B. Systematic review of focal prostate brachytherapy and the future implementation of image-guided prostate HDR brachytherapy using MR-ultrasound fusion. Prostate Cancer 2016;2016:4754031

[48] Srougi V, Barret E, Nunes-Silva I, et al. Focal brachytherapy for localized prostate cancer: urinary toxicity depends on tumor location. Brachytherapy 2017;16:988-92.

[49] Nguyen PL, Chen MH, Zhang Y, et al. Updated results of magnetic resonance imaging guided partial prostate brachytherapy for favorable risk prostate cancer: implications for focal therapy. J Urol 2012;188:1151-6.

[50] Mahdavi SS, Spadinger IT, Salcudean SE, et al. Focal application of low-dose-rate brachytherapy for prostate cancer: a pilot study. J Contemp Brachyther 2017:9:197-208.

[51] Haffner MC, Mosbruger T, Esopi DM, et al. Tracking the clonal origin of lethal prostate cancer. J Clin Invest 2013;123:4918-22.

[52] Liu W, Laitinen S, Khan S, et al. Copy number analysis indicates monoclonal origin of lethal metastatic prostate cancer. Nat Med 2009; 15:559-65.

[53] Le JD, Tan N, Shkolyar E, et al. Multifocality and prostate cancer detection by multiparametric magnetic resonance imaging: correlation with whole-mount histopathology. Eur Urol 2015;67:569-76.

54] Ramsay CR, Adewuyi TE, Gray J, et al. Ablative therapy for people with localised prostate cancer: a systematic review and economic evaluation. Health Technol Assess 2015;19:1-490.

[55] Donovan JL, Hamdy FC, Lane JA, et al. Patient-reported outcomes after monitoring, surgery, or radiotherapy for prostate cancer. $\mathrm{N}$ Engl J Med 2016;375:1425-37.

[56] Ahmed HU, Hindley RG, Dickinson L, et al. Focal therapy for localised unifocal and multifocal prostate cancer: a prospective development study. Lancet Oncol 2012;13:622-32.

[57] Linares Espinos E, Sanchez-Salas R, Sivaraman A, et al. Minimally invasive salvage prostatectomy after primary radiation or ablation treatment. Urology 2016;94:111-6.

[58] Lebdai S, Villers A, Barret E, Nedelcu C, Bigot P, Azzouzi AR. Feasibility, safety, and efficacy of salvage radical prostatectomy after $\operatorname{Tookad}(\mathrm{R})$ soluble focal treatment for localized prostate cancer. World J Urol 2015;33:965-71. 
Focal Therapy in Primary Localised Prostate Cancer $<$ ce:italic $>:</$ ce:italic $>$ The Europ... Page 8 of 8

[59] Stone NN, Unger P, Crawford ED, Stock RG. Diagnosis and management of local recurrence after low-dose-rate brachytherapy. Brachytherapy 2015;14:124-30.

[60] van Stam MA, Aaronson NK, Pos FJ, et al. The effect of salvage radiotherapy and its timing on the health-related quality of life of prostate cancer patients. Eur Urol 2016;70:751-7.

[61] Ghadjar P. Hayoz S, Bernhard J, et al. Acute toxicity and quality of life after dose-intensified salvage radiation therapy for biochemically recurrent prostate cancer after prostatectomy: first results of the randomized trial SAKK 09/10. J Clin Oncol 2015;33 4158-66.
[62] Siddiqui KM, Billia M, Arifin A, Li F, Violette P, Chin JL. Pathologic, oncologic and functional outcomes of a prospective registry of salvage high intensity focused ultrasound ablation for radio-recurrent prostate. J Urol 2017:197:97-102.

[63] Chade DC, Eastham J, Graefen M, et al. Cancer control and functional outcomes of salvage radical prostatectomy for radiation-recurrent prostate cancer: a systematic review of the literature. Eur Urol 2012;61:961-71.

[64] Nunes-Silva I, Barret E, Srougi V, et al. Effect of prior focal therapy on perioperative, oncologic and functional outcomes of salvage robotic assisted radical prostatectomy. J Urol 2017;198:1069-76.

\section{SEEM18}

\section{EAU 13th South Eastern}

European Meeting

21-22 September 2018, Belgrade, Serbia
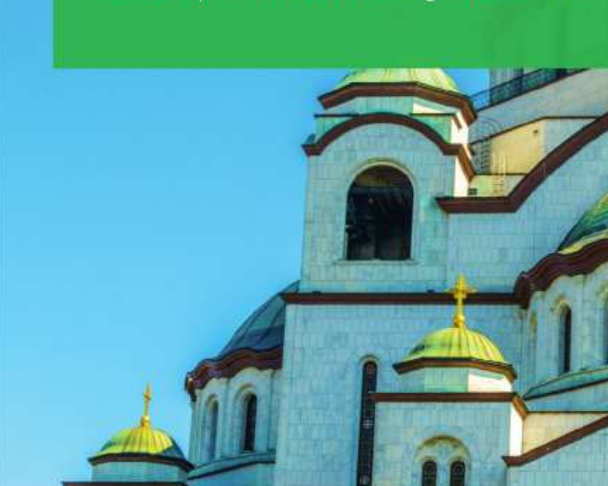

www.seem18.org

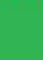

